\title{
Materials Research Facilities Dialogue
}

On the evening of Thursday, December 5, 1985 in Boston, MRS hosted a gathering of prominent materials researchers who discussed many issues surrounding the technical, funding, and societal aspects of large facilities for materials research and of small and intermediate size research efforts in today's university, industrial, and government laboratory settings. Invited discussants and observers at the Materials Research Facilities Dialogue were:

B. W. Batterman,

CHESS, Cornell University

A. I. Bienenstock, SSRL Stanford University

W. L. Brown,

ATET Bell Laboratories

M. S. Dresselhaus, MIT

C. B. Duke, Xerox

P. M. Eisenberger, Exxon

H. H. Johnson, Cornell University

W. L. Johnson, Caltech

M. L. Knotek,

Brookhaven National Laboratory

R. A. Laudise,

ATET Bell Laboratories

J. W. Mayer, Cornell University

R. M. Moon,

Oak Ridge National Laboratory

J. J. Rush,

National Bureau of Standards

L. H. Schwartz,

National Burean of Standards

P. A. Wolff,

MIT, National Magnet Laboratory

D. E. Moncton (Observer), Brookhaven National Laboratory

C. W. White (Observer), Oak Ridge National Laboratory

F. W. Young (Observer), Oak Ridge National Laboratory

G. A. Oare (Recorder), Materials Research Society

E. N. Kaufmann (Facilitator), Lawrence Livermore National Laboratory

The sole purpose of the gathering was to discover existing areas of agreement among the participants on issues over which considerable public debate has arisen. The event grew from a suggestion by Peter Eisenberger of Exxon that an MRS forum might serve to produce a constructive dialogue among presumed protagonists around the topic of large scale facilities and small scale science, thereby "reducing the noise level and increasing the coherent signal" to the extent possible.

Very clear areas of consensus were found to exist. They can be stated as follows:

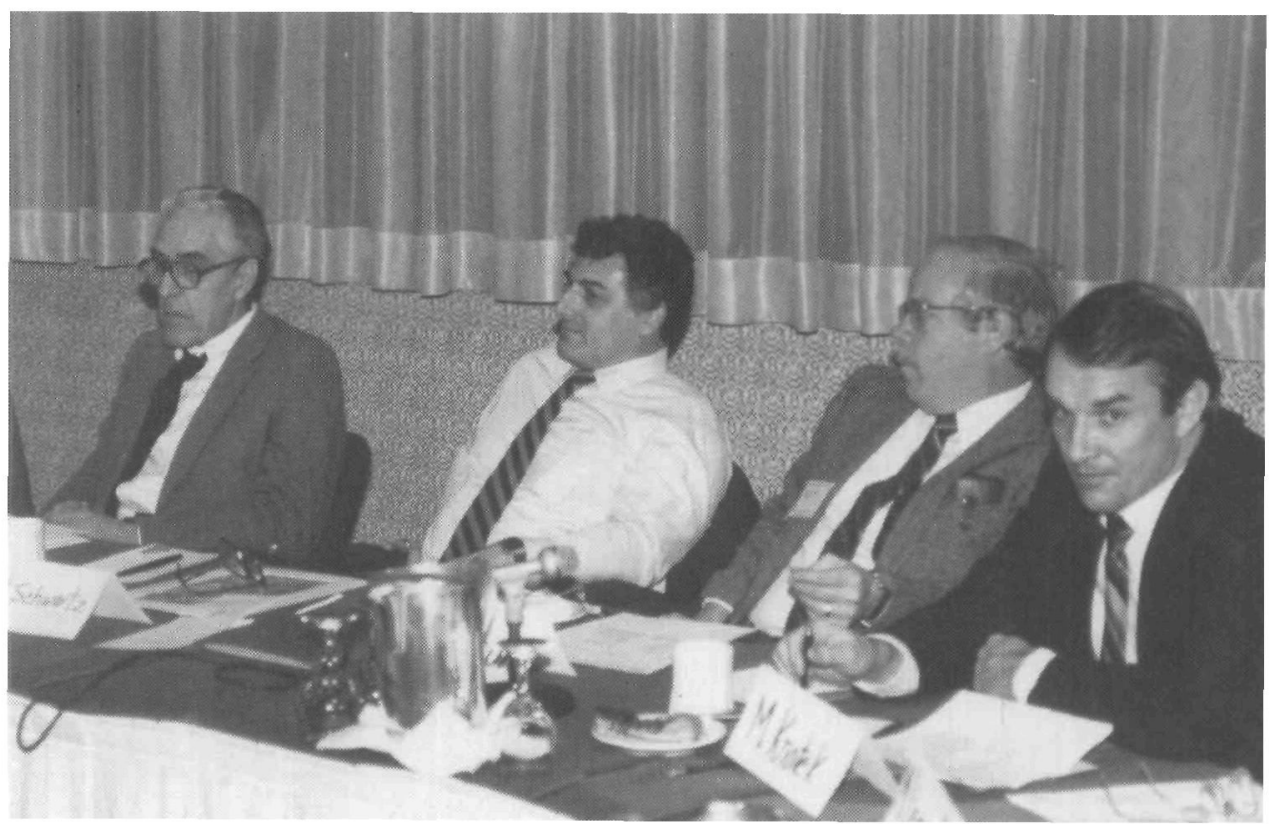

Left to right: R.M. Moon, L.H. Schwartz, H.H. Johnson, and M.L. Knotek.

The clear present and future impact of advanced materials on crucial national economic and security goals in the U.S. has not been enunciated by the materials research community in such a way and from such a source that the administration and congressional funding priorities reflect a recognition of this connection. In other words, "the customer has not been clearly shown the product and its value to the customer's constituency."

More relevant than the question of how to allocate resources from a "fixed pie" is the question of how to increase the overall "size of the pie." To do the latter, the case must be made concerning the above referenced connection of materials research to major national goals.

The materials research community has evolved such that its diverse interests, specialities, and points of view are more visible than its common interest. No unified voice or generally accepted spokesgroup exists to effectively represent materials research interests. Intimately related to this lack is the tendency for members of the materials research community to publicly vie for support of their special interest in such a way that the lack of unanimity sends no clear message to sources of support. It would be constructive to support all items funding materials research that reach the President's budget, whether or not one's own interest is included.

The present mind set of the typical materials researcher reflects the individual in the laboratory without connection to a socio-political organization because the need for such a group had not arisen. It is recognized that to move from the present condition of relative disarray to one with strongly supported unified representation entails a period of transition for the community during which patience and forbearance, with an as yet not fully representative and therefore imperfect spokesgroup, will be required.

One purpose of the Study of Materials Science and Engineering begun jointly by the Solid State Sciences Committee (SSSC) of the National Academy of Science and the National Materials Advisory Board (NMAB) of the National Academy of Engineering is recognized as an attempt to resolve the "no single voice" problem. It is hoped that it succeeds in this regard, however, the time scale of the study is such that many opportunities for improved support may be missed in the interim.

For clear historical reasons, the existing funding agency structure reflects a variety of missions each of which is only -partly dependent on materials research. As a result, there is no apparent government mechanism to implement the "regaining and retaining of preeminence in advanced materials related fields (such as electronics, optics, structural, etc.)" as a primary mission. To substantively adjust the structure, the national consciousness may need to be 
Continued from preoious page

raised for this challenge as it has been in the past for space exploration and fighting disease.

One step in the direction of providing unified and consistent advice to government could be the amalgamation of the SSSC and the NMAB by the Academies.

Independent initiatives directed at specific appropriation legislation in the Congress, which circumvent the possibility of inclusion in a unified statement of the needs of the field, are counterproductive in the long run.

Many forefront areas of materials research now require the availability of the large facilities to make significant advances and these facilities provide a vital and cost effective service to those individual researchers who work in those areas. Many more individual researchers engaged in areas of forefront research do not benefit directly from the large facilities. The nature of the large facility is such that a coherent constituency develops which can state the needs of the facility in a visible fashion, whereas no analogous mechanism operates in favor of the non-facility-related research.

The state-of-the-art entry cost for most areas of materials research is rising beyond the ability of the individual university researcher to handle. Increased support of industry in this regard would be appropriate, particularly because a primary product of the university research is the highly trained graduate employed by industry. It is recognized, however, that the scale of support needed is of such magnitude that the major responsibility will continue to rest with government.

All participants in this discussion were pleased and enthused with the high degree of consensus achieved. This was so much the case that a desire was expressed in various forms to initiate some action, particularly with regard to the need to make the case at the appropriate levels of government for the direct relevance of strongly supported materials research to the economic health and the national security of the U.S.

Before adjourning, the group suggested that the MRS Council be asked to publicly address this issue. Subsequently, the Council was briefed on the results of the Dialogue and issued the statement reproduced in the box on this page. In discussing what organizations might join in some form of unified voice for our comm unity, MRS was one of several mentioned. MRS accepts as part of its responsibility to materials researchers the role of facilitator, organizer, and host for a variety of activities related to our field. Dialogues such as occurred on December 5 are one way MRS can contribute. The Society would welcome further opportunities, singly and in conjunction with sister organizations, to bring a strong and unified perception and reality to the materials research community.

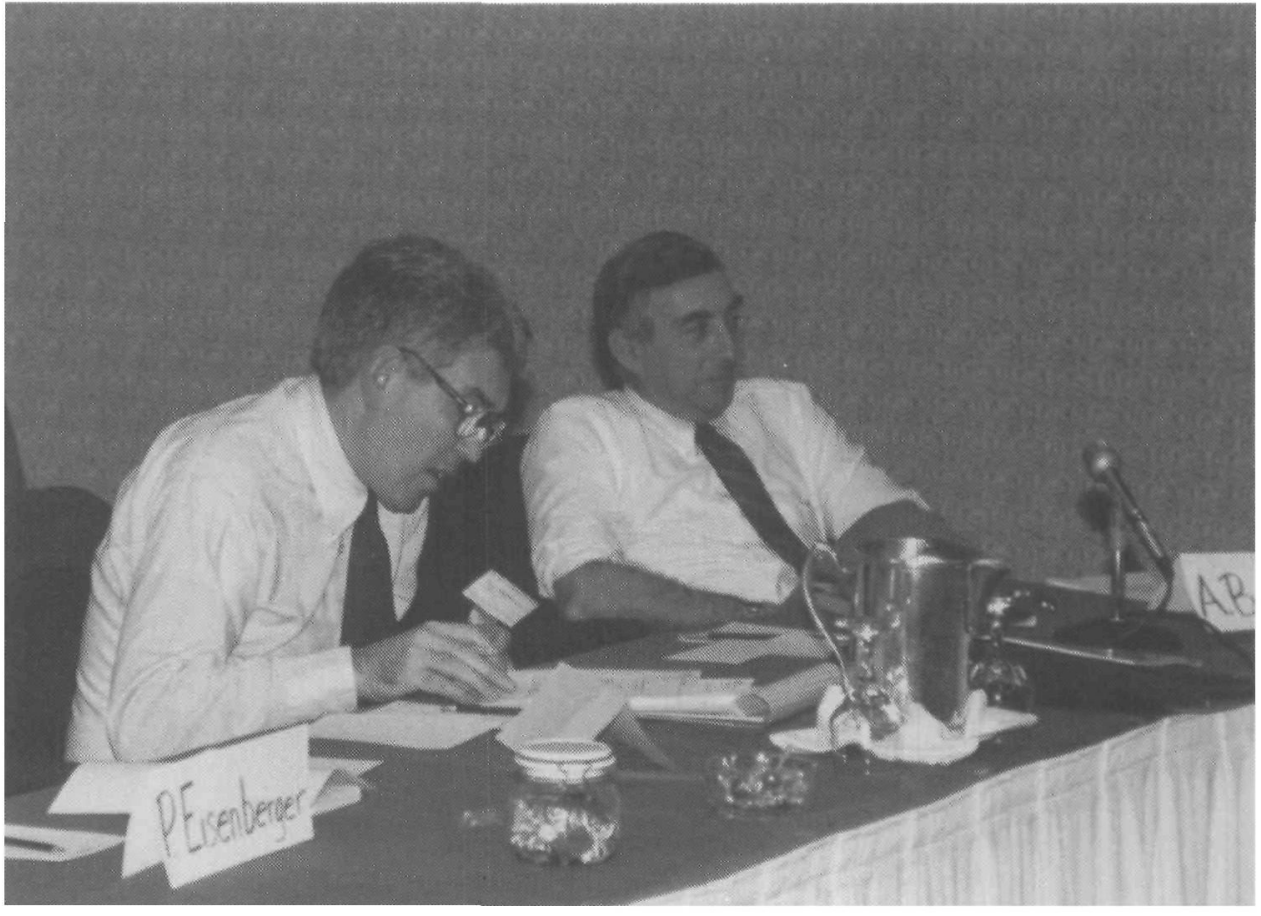

Left to right: P.M. Eisenberger and A.I. Bienenstock.

\section{Statement Issued By MRS Council}

The Materials Research Society is one of the principal organizations whose membership is broadly involved in the materials research of the country, and hence is vitally concerned with the development of more effective, representative, and coherent means for identification of national economic and security goals which depend on materials research. These issues are now heard through many different and often highly discordant channels. The efforts of the committees of the Academies of Science and Engineering to jointly develop a coherent channel for this purpose are strongly encouraged as are efforts within existing national funding agencies to develop coherent planning and evaluation strategies.

The Materials Research Society understands the importance to materials research of the diversity of facilities and research style on which progress in this broad and multidisciplinary field depends. Materials preparation and diagnostic tools in individual scientific laboratories as well as access to the specific capabilities of major national facilities play complementary roles in these research programs. The innovative and leadership capabilities of members of $M R S$ can be valuable resources in establishing a balanced national policy for materials research and development, which is sorely needed. We urge that these capabilities of the Society in the materials work of the nation be utilized in this objective.

MRS Council Boston, December 7, 1985 